\title{
Effect of vibrissal amputation or anesthesia on rearing behavior in rats
}

\author{
ERNEST D. KEMBLE and JENNIFER A. NAGEL \\ University of Minne sota-Morris, Morris, Minnesota 56267
}

\begin{abstract}
Open-field rearing behavior was observed in rats following vibrissal amputation or anesthesia. Vibrissal anesthesia produced striking changes in the form of open-field behavior and increased the frequency of grooming bouts but neither treatment reliably affected rearing behavior.
\end{abstract}

Extensive septal lesions in rats produce a persistent reduction in rearing behavior (Dirlam, 1969; Kemble \& Nagel, 1975; Donovick, Burright, \& Swidler, 1973). Septal lesions also disrupt normal vibrissal movements (Gray, 1971), producing a decrease in the vigor, regularity, and synchrony of these movements. Damage to this area also disrupts hippocampal theta rhythm (Donovick, 1968) which, in turn, is closely correlated with vibrissal movements (Komisaruk, 1970) and with exploratory behavior (Vanderwolf, 1969). Thus, it is possible that septal lesion effects on rearing reflect a disruption of normal vibrissa function. If so, other manipulations which interfere with vibrissal function might also alter rearing behavior. These experiments investigate the effect of vibrissal amputation or local anesthesia of mystacial vibrissal pads on rearing.

\section{EXPERIMENT I}

\section{Method}

Subjects. The subjects were 12 experimentally naive male albino rats weighing 295-368 $\mathrm{g}$ at the time of the test. All subjects were lightly etherized 50-60 min before testing and the mystacial. superciliary. submental, interramal, and genal vibrissae of six (experimental) rats were amputated within $2-5 \mathrm{~mm}$ of the skin with scissors. The remaining (control) subjects were simply returned to their home cages. All animals appeared quite normal, with no discernible anesthetic effects. during the test.

Apparatus. Rats were tested in a $72.4 \times 61.0 \times 63.5 \mathrm{~cm}$ open field. Three walls and the floor were of plywood (flat gray), and the remaining wall was of clear Plexiglas. A $60-\mathrm{W}$ bulb mounted in the ceiling provided illumination, and extraneous sound was masked by $90-\mathrm{dB}$ white noise. The floor was divided into $20.3 \times 24.1 \mathrm{~cm}$ rectangles by thin black lines. Further details are available in an earlier publication (Kemble \& Nagel. 1975).

Procedure. Each rat was gently placed in the center of the open tield and the number of rearing responses (whenever both forepaws were lifted from the floor) tallied for eight consecutive 1-min intervals. The number of fecal boluses excreted during the 8 -min test were also tallied.

\section{Results}

The rearing behavior of both experimental and

This research was supported in part by the Graduate School, University of Minnesota. control groups declined steadily during the open-field test $[F(7 / 70)=14.20, p<.01]$. However, there was no suggestion of group differences $(F<1.0)$ and no Treatment by Intervals interaction $(F<1.0)$. Number of fecal boluses excreted was also comparable in both groups $(\mathrm{p}>.10, \mathrm{U}$ test $)$.

\section{EXPERIMENT II}

Although vibrissal amputation clearly did not decrease rearing behavior, this operation did not interfere with the reception of tactile information from this area or with the musculature controlling synchronized vibrissa movement. Such movements were clearly present in Experiment I and could have contributed importantly to exploratory behavior. The present study attempted to eliminate these sources of information by the subcutaneous injection of a local anesthetic in the region of the vibrissae.

\section{Method}

Subjects. The subjects were 12 experimentally naive albino rats weighing $358-410 \mathrm{~g}$ at the time of testing.

Procedure. All subjects were lightly anesthetized with ether 45-50 min before testing, and .1 ml of Xylocaine hydrobromide was injected subcutaneously under the mystacial vibrissae on each side of the snout (total $.2 \mathrm{ml}$ ) in six (experimental) animals. The remaining (control) subjects received an equivalent injection of isotonic saline. Rearing and activity (number of rectangles entered) were measured for $10 \mathrm{~min}$ (four $21 / 2$-min intervals) in the open field. Number of grooming bouts and rears lasting $3.0 \mathrm{sec}$ or longer (estimated) were also recorded in this experiment.

\section{Results and Diacussion}

As in the previous experiment, there were no discernible residual effects of ether anesthesia when the subjects were tested. Synchronous vibrissa movements returned very promptly (1-2 min) after anesthesia in control animals and appeared normal during testing. The effects of Xylocaine, on the other hand, were prompt and dramatic. Synchronous vibrissa movement did not return after recovery from ether and only occasional spasmodic bilateral or unilateral vibrissal movements were noted during testing. These animals appeared quite clumsy, often 
ran into walls, and spent a great deal of the time in their home cage or the open field with their snouts pressed firmly against the wall. This form of behavior was never observed in control animals. Xylocainetreated subjects also engaged in frequent and intense grooming bouts both in their home cages and in the open field.

The rearing behavior of both groups declined steadily during testing $[\mathrm{F}(3 / 30)=11.55, \mathrm{p}<.01]$ but there were no reliable group differences $[F(1 / 10)=2.0]$ or Treatment by Intervals interaction $(F<1.0)$. Experimental subjects engaged in significantly more grooming bouts $(\bar{X}=15.85)$ than control subjects $[\overline{\mathrm{X}}=5.16, \mathrm{U}(6 / 6)=0, \mathrm{p}<.01]$. The groups did not differ, however, in the number of rears exceeding $3.0 \mathrm{sec}$ in duration $(\mathrm{p}>.10, \mathrm{U}$ test). It should also be noted that there were no obvious qualitative or quantitative group differences in rearing during nongrooming behavior.

Although vibrissal anesthesia produced obvious changes in the form of open-field behavior and greatly increased the frequency of grooming, there was no discernible effect of this treatment, or amputation, on rearing behavior. Thus, septal lesion effects on rearing do not seem to result from altered vibrissal function. These data are consistent with the suggestion (Kemble \& Nagel, 1975) that lesion effects on rearing do not reflect altered responsiveness to stimuli.

\section{REFERENCES}

Dirsam, D. K. The effects of septal, thalamic, and tegmental lesions on general activity in the hooded rat. Canadian Journal of Psychology. 1969. 23. 303-314.

Donovick. P. J. Effects of localized septal lesions on hippocampal EEG activity and behavior in rats. Journal of Comparative and Physiological Psychology, 1968. 66, 569-578.

Donovick. P. J.. Burright, R. G., \& Swidler, M. A. Presurgical rearing environment alters exploration. fluid consumption. and learning of septal lesioned and control rats. Physiology and Behavior. 1973. 11, 543-553.

GraY, J. A. Medial septal lesions, hippocampal theta rhythm and the control of vibrissal movement in the freely moving rat. Electroencephalography and Clinical Neurophysiology, 1971, 30. 189-197.

Kemble, E. D.. \& Nagel, J. A. Persistent depression of rearing behavior in rats after extensive septal lesions. Journal of Comparative and Physiological Psychology, 1975, 89. 747.758.

KomisaruK, B. R. Synchrony between limbic theta activity and rhythmical behavior in rats. Journal of Comparative and Physiological Psychology, 1970, 70, 482-492.

VANDERWOLF, C. H. Hippocampal electrical activity and voluntary movement in the rat. Electroencephalography and Clinical Neurophysiology, 1969, 26, 407-418.

(Received for publication January 8, 1976.) 